\title{
Modelling of motorway bridge spans under modernization with consideration of rheological properties of the materials
}

\author{
Alexey Lobiak ${ }^{*}$, Andrii Plugin ${ }^{2}$, Larisa Kravtsiv ${ }^{1}$, and Oksana Kovalova ${ }^{3}$ \\ ${ }^{1}$ Ukrainian State University of Railway Transport, Structural Mechanics and Hydraulics Department, Feuerbach sq. 7, 61050 Kharkiv, Ukraine \\ ${ }^{2}$ Ukrainian State University of Railway Transport, Building Materials and Structures Department, Feuerbach sq. 7, 61050 Kharkiv, Ukraine \\ ${ }^{3}$ Ukrainian State University of Railway Transport, Manage freight and commercial work Department, Feuerbach sq. 7, 61050 Kharkiv, Ukraine
}

\begin{abstract}
The paper presents a computer modelling technique for modernization of bridgework operations by building-up a mounted reinforced concrete slab. It implements the technique of the evolutionary transformation of a model in one calculation cycle with redistribution of forces between the elements of the built-up section, and consideration of the impact of elastoplastic and rheological properties of the materials. Consideration of the concrete creep implies the application of the generalized kinetic curve of prolonged deformation and phenomenological deformation development equations based on the colloid-chemical concept of the prolonged concrete deformation mechanism. The creep control was implemented through new structural coefficients which determined the structure of matrix interlayers between the sand grains, and mortar between the crushed stone grains. The technique proposed was realized in the program complex "LIRA-SAPR" based on the building information modelling (BIM) and the finite element method (FEM). The multistage modelling technique was shown by an example of calculation of a motorway bridge slab span within the transport structures under modernization along the Lev Landau Avenue in Kharkiv (Ukraine).
\end{abstract}

\section{Introduction}

According to the State Agency of Automobile Roads of Ukraine, the total length of the road network in Ukraine is over 172000 kilometers. And in the long term we are going to witness both dynamic construction of new roads and modernization of existing ones in order to handle much heavier traffic flows which may lead to greater loads on engineering structures including bridges and overpasses. At the same time, we constantly notice the overrunning of the building norms and basic loads with which new and existing bridgeworks should conform. In turn, change in the building norms and increase in the loads from transportation means may require modernization of spans and bring their loading capacity into conformity with the requirements. Besides, bridgeworks constantly suffer from various defects and damages due to the climatic conditions and unavoidable physical depreciation.

At present, in Ukraine a great many existing road bridgeworks do not satisfy the modern requirements for carrying capacity, traffic area dimensions and engineering state. One of the most common modernization techniques for bridge spans is the building-up of a mounted solid concrete reinforced slab. The advantage of this reinforcement technique is the monolithic action of the prefabricated span elements in transverse direction, which increases the carrying capacity and eliminates "the key effect". For slab spans of road bridges this problem is most acute as in operation their key connections often damage.

The efficiency of span modernization with a mounted slab is calculated in the design stage, and, first of all, depends on the model adequacy. However, the existing building norms of Ukraine [1] do not provide this design procedure which complicates the application of the modernization method. The paper deals with practical experience in finite-element modelling of the span operation through an example of road overpass considering the operation stages from the current state to latest service life periods after modernization. The technique proposed implements the evolutionary transformation of a model in one calculation cycle with consideration of the impact of elastoplastic and rheological properties of the materials.

\section{A model of the span operation}

\subsection{Problem statement}

The effect of the increased carrying capacity of a span by building-up a mounted slab depends on the technological maintenance diagrams accepted and existing technical state of the structure. Taking into account that the mounted slab in modernization is put into operation for the second part of the constant and the temporary loads, the calculation was done non-linearly considering

\footnotetext{
* Corresponding author: Lobiak@ukr.net
} 
changes in the structure. And at each stage of the evolutionary changes the calculation should be done for a corresponding construction diagram considering the mounted elements. For this case the design procedure considered three mounting stages (Fig. 1) and redistribution of forces as a result of the structural changes and concrete creep. The effect of the concrete creep was considered on the basis of a method developed by the authors and proven to be effective in earlier research into composite [2] and concrete structures [3].

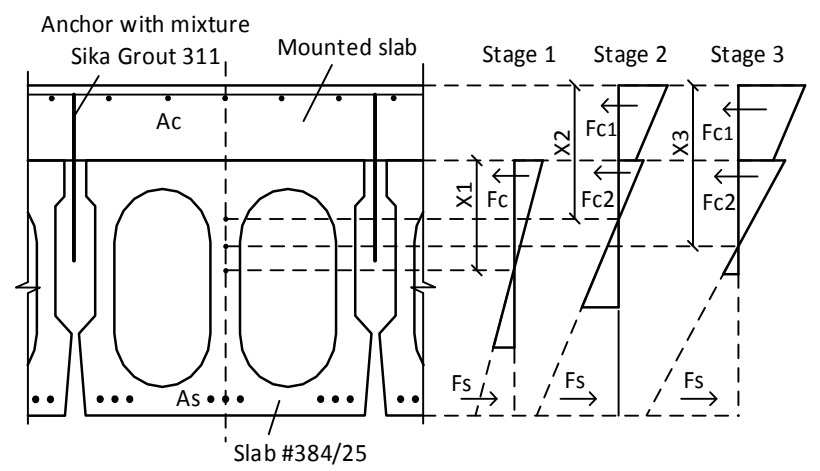

Fig. 1. Stages of the span operation.

The first stage involves the loading of the existing span elements with the first part of the constant loads consisting of the weight of the initial and built-up elements (a mounted slab), as well as the forces of the reinforcement pre-stress. The second stage puts the mounted slab into operation, and the composite section bears the additional loads from the weight of the road pavement, sidewalk blocks and road guards. The third stage implies the combination of constant and temporary loads. Here, the carrying capacity is assessed separately for the existing elements of the span and the reinforcement elements.

Generally, the design of transport facilities at present assumes the application of industrial program complexes as the basic computer modelling tool. The method proposed was fully realized with the program complex LIRA-SAPR [4]. The extensive library of finite elements (FE), support of the non-linear material behavior and powerful analyzing tools provided the needed functionality in the numerical analysis of reinforced structures.

\subsection{The concrete creep}

Numerous experiments demonstrate that concrete-based structures under long-term loads suffer from non-elastic deformations, which can exceed the initial conditionally elastic ones several times. But for bridge works of reinforced concrete and composite structures the problem of concrete creep is most acute. Thus, the problems of long-term deformation forecasting for bridge works, as well as synchronous redistribution of loads in the composite sections of spans, are rather urgent.

The existing creep theories widely use two approaches in forecasting long-term deformations. According to the first one, material behavior is based on mechanical systems made of combination of elements intended for mechanical property modelling (module of elasticity and viscosity coefficient). The second approach, the phenomenological one, is based on experimental data establishing dependencies between deformations and time (creep curves) or stress and time (relaxation curves). The existing phenomenological theories, despite the success achieved, do not accurately consider concrete creep deformations. Particularly, the most general hereditary theory of concrete ageing connects residual deformations with ageing only, excluding the part of residual deformation which is the result of the stresses and change in the concrete structure.

The Building Norms of Ukraine, harmonized with Eurocode 2 [5], are based on the simplest approach establishing dependencies between deformations and time with the creep coefficient $\varphi\left(t, t_{0}\right)$. According to this method, ultimate deformations of creep depend on concrete strength, age and relative moisture, and creep development in time $t$ depends on the relative moisture and section size:

$$
\varepsilon_{c, t}=\sigma_{c} / E_{c}\left[1+\varphi_{0} \beta\left(t, t_{0}\right)\right],
$$

where $\beta\left(t, t_{0}\right)$ is coefficient describing the development of creep over time; $t_{0}$ - age of the concrete at the time of the first load.

The method realizes $90 \%$ of concrete creep deformations in a life span of 20-25 years. Despite its advantages, this method cannot reveal the actual mechanism of long-term deformations of concrete, and thus, does not allow us to control the mechanism and influence the ultimate values of creep deformations.

Since alternative methods to consider the creep can be applied with special software, we propose a method based on the colloidal chemical representation of the mechanism of long-term concrete deformations [3].

The theory is based on a more accurate representation of the kinetic concrete deformation curve (Fig. 2). On the basis of the findings of the study, the equations of deformation development were obtained depending on four stages of concrete performance: compression in the conditionally elastic setting, the stage of high-rate creep (1), ordinary creep, consisting of nonlinear (2) and linear (3) parts, as well as long-term creep (4).

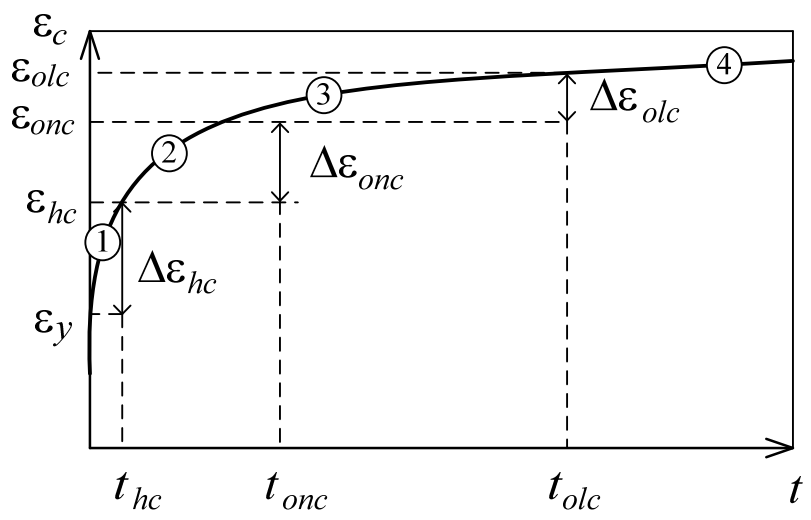

Fig. 2. The generalized kinetic concrete creep nomogram. 
In accordance with Fig. 2, the pattern of the long-term deformation of the concrete under compression and the general concrete deformation equation take the form:

$$
\varepsilon_{c}=\varepsilon_{y}+\Delta \varepsilon_{h c}+\Delta \varepsilon_{\text {onc }}+\Delta \varepsilon_{\text {olc }}+\Delta \varepsilon_{1 c} .
$$

The specific equations simulating deformation kinetics at each of the above stages:

$$
\begin{gathered}
\varepsilon_{c, h c}(t)=\varepsilon_{y}+\Delta \varepsilon_{h c}\left(1-e^{-t / T_{r}^{h c}}\right) ; \\
\varepsilon_{c, o n c}(t)=\varepsilon_{h c}+\Delta \varepsilon_{o n c}\left(1-e^{-t / T_{r}^{o n c}}\right) ; \\
\varepsilon_{c, o l c}(t)=\varepsilon_{\text {onc }}+k_{\text {olc }}\left(t-t_{\text {onc }}\right) ; \\
\varepsilon_{c, l c}(t)=\varepsilon_{\text {olc }}+k_{1}\left(t-t_{\text {olc }}\right),
\end{gathered}
$$

where $T_{r}^{h c}, T_{r}^{o n c}$ are relaxation time according to the Tertsagi's dispersion phase model on the exponential deformation stages; $k_{\text {olc }}, k_{l}-$ kinetic coefficients reflecting a rate of general (on the linear section) and long-term creep deformation.

In view of the latter, the expression for determining the creep coefficient at any concrete deformation stage takes the form:

$$
\varphi(t)=\left\lfloor\varepsilon_{c}(t)-\varepsilon_{\mathrm{c}, \mathrm{y}}\right\rfloor / \varepsilon_{c, y} .
$$

The total relative concrete deformations, corresponding to the completion of the high-rate $\left(\varepsilon_{h c}\right)$ and ordinary $\left(\varepsilon_{o n c}, \varepsilon_{o l c}\right)$ creep stages, are determined on the basis of the hypothesis about the behaviour mechanism of submicroscopic structure of the concrete consisting of electrically charged particles (globules) of hydrosilicate gel when it is exposed to compressing load. It is assumed that ultimate creep deformations are determined by gel deformations due to compression of a double electric layer, water filtration from the compressed areas of the construction into those stretched according to the pressureless water penetration law, while the long-term creep kinetics depends on the scale factor during filtration of water squeezing from the gel.

Creep deformations can be controlled through new structural coefficients determining the structure of cement stone layers between the sand and mortar grains between chip grains [3]:

$$
\begin{gathered}
\alpha=V_{c s m} / V_{e m p}^{B S}=\left(\frac{S}{\rho^{S}}+\frac{C}{\rho^{C}}+\frac{W}{\rho^{W}}\right) /\left(\frac{B S}{\rho_{\text {pour }}^{B S}} \cdot S_{\text {emp }}^{B S}\right) \\
\mu=V_{c s} / V_{\text {emp }}^{S}=\left(\frac{C}{\rho^{C}}+\frac{W}{\rho^{W}}\right) /\left(\frac{S}{\rho_{\text {pour }}^{S}} \cdot S_{\text {emp }}^{S}\right)
\end{gathered}
$$

The best coefficients $\alpha_{o p t}$ and $\mu_{\text {opt }}$ were obtained under the condition of the fullest contact, which decreases disjoining pressure and, respectively, compressive deformations and hair cracks.

\section{Realization of the method}

\subsection{Constructive solution}

The design calculation of an overpass within the transport structures under modernization along the Lev Landau Avenue in Kharkiv (Ukraine) is an example of a multistage modelling technique proposed. The span consists of 31 pre-stressed slabs of a length of $12 \mathrm{~m}$ and a thickness of $600 \mathrm{~mm}$ with oval hallows. The carrying structures are made for loads H-30 (the load from a convoy of 50-ton trucks) and HK-80 (the wheel load from a convoy of 80-ton trucks) in accordance with a standard project of series 3.503-12 inventory \# 384/25 "Soiuzdorproekt". The ultimate bending moment of the section in accordance with the standard design is $M_{u}=541.3 \mathrm{kNm}$ with the consideration of the partial loss of concrete strength being $M_{u f}=520.66 \mathrm{kNm}$. According to the routine inspection of the technical state and calculations, the experts recommended refurbishment of the overpass due to its disabled state (State 5 by Classification [6]).

The span modernization involved (Fig. 1) the installation of a solid reinforced concrete mounted slab with a minimal thickness of $150 \mathrm{~mm}$ put into operation with the existing span slabs with anchors. The anchors were fixed in restored monolithic sections of the seams with the selfleveling cement epoxy mixture SikaGrout 311 . The slab was installed without preliminary unloading of the spans.

\subsection{The design diagram}

The following hypotheses were taken for designing a finite element model of the span.

1. The existing span slabs were modelled with universal spatial axial FEs considering physical non-linearity. The mounted slab was modelled with FEs of thin shallow shells as a biomaterial system of isotope physicallynonlinear materials.

2. The flexibility of links between the sectional elements was provided with resilient filling pieces of constant rigidity in shearing, which physically modelled the anchor devices. The pre-stress forces of the reinforcement were set with a group of FEs "hung" to the rods with rigid filling pieces.

3. The structural non-linearity of the system was revealed with the design method "Mounting" which considered the evolutionary transformations. Besides, each building stage had the finite elements specified for it. And the load corresponding to this stage was calculated. For finite elements included for several stages all the efforts were summed up.

4. The concrete strength and stress-strain behaviour were characterized by parabolical and linear stress-strain diagrams $\sigma_{c}-\varepsilon_{c}$ according to the grade, and also by longterm deformation diagrams $\varphi(t)-t$. In order to consider the reinforcement steel, the diagram $\sigma_{s}-\varepsilon_{s}$ without the yield line was applied.

The span model was made according to statistically determinate diagram and hinged edges. 
Generally, the design diagram was drawn up of materially nonlinear FEs of slabs simulating operation of the mounted slab, FE grid frameworks, a group of rigid inserts to transfer forces of pre-tension and a group of flexible inserts for "hanging" precast elements of the existing span (Fig. 3).

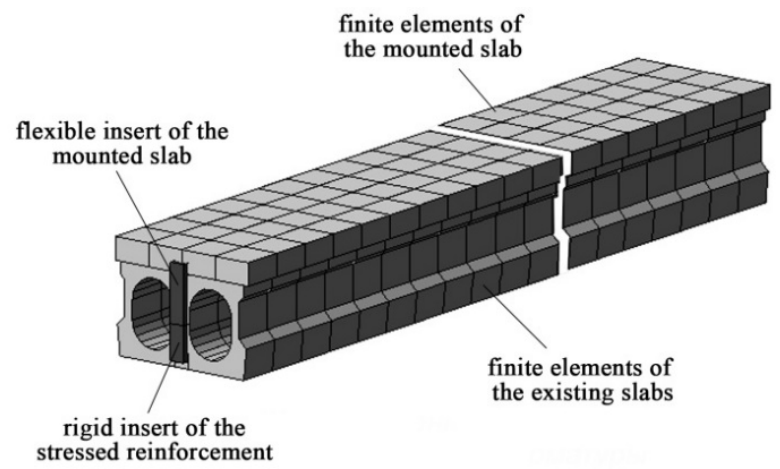

Fig. 3. A fragment of the span model.

The triangulation diagram was obtained as the solution of a separate task to seek a compromise between time and calculation accuracy.

The calculation was done using the iterative and incremental method by three mounting stages considering the creep at two first stages (Fig. 1). The number of loading steps at each mounting stage was 50, and the increase at each step was irregular. The shear rigidity along the contact of the composite section was defined by the number and types of anchors.

The creep calculation considered the relative humidity $\mathrm{RH}=74 \%$ and the age of concrete of the mounted slab to be 28 days. The creep nomograms obtained according to [5] and the method proposed are presented in Fig. 4. The software specified the dependency proposed in the description of the stress-strain properties of the concrete as the axis set of a piecewise linear diagram.

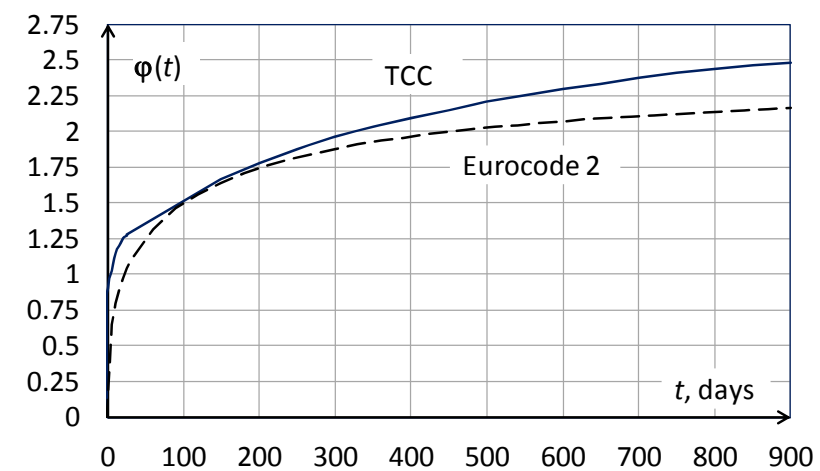

Fig. 4. The creep nomograms obtained in accordance with Eurocode 2 and the method proposed (TCC - stands for the theory of colloid chemistry).

\subsection{The results of the calculation}

First and foremost, the calculation objective was a selection of the rational size of the mounted slab at a given concrete grade providing due operability of the overpass (State 3 by Classification [6]) at minimal added dead weight of the span.
The operational states of bridges presented in the Ukrainian Building Norms are classified by a safety indicator according to the reliability evaluation model put forward by A.R. Rzhanitsin [7]

$$
\beta=\frac{\gamma-1}{\sqrt{V_{q}^{2}+\gamma^{2} V_{r}^{2}}}
$$

Formula $\gamma$ presents the mathematical expectation of the generalized safety coefficient, which, in this case, can be represented as the relation of the ultimate moment $M_{u}$ to the design moment of the existing span elements $M_{s l}$

$$
\gamma=\frac{M_{u} B_{r}}{M_{s l} B_{q}}
$$

where $V_{q}$ and $V_{r}$ are generalized coefficients of influences and resistances

$$
B_{r}=\frac{1}{1-1.64 V_{r}} ; B_{q}=\frac{1}{1+1.64 V_{q}} \text {. }
$$

The generalized coefficients of the variations are defined by the general formulae of quadratic deviation of the sum of mutually independent variables taken by statistical models of loading and resistance of the system. Thus, the adopted statistical models are presented in Tables 1 and 2.

Table 1. The statistical model of effects.

\begin{tabular}{|l|r|}
\hline \multicolumn{1}{|c|}{ Random factor } & \multicolumn{1}{c|}{$\boldsymbol{V}_{\boldsymbol{q}}$} \\
\hline Dead weight of the span & 0.033 \\
\hline Bogie load A-11 & 0.17 \\
\hline Uniform load A-11 & 0.24 \\
\hline Roadway and pavement load & 0.17 \\
\hline Pedestrian load & 0.24 \\
\hline Cross-section moment & 0.0229 \\
\hline Cross-section area & 0.0237 \\
\hline Eccentricity of pre-stress forces & 0.0167 \\
\hline Shrinkage and creep effect & 0.03 \\
\hline
\end{tabular}

Table 2. The resistance statistical model.

\begin{tabular}{|l|r|}
\hline \multicolumn{1}{|c|}{ Random factor } & \multicolumn{1}{c|}{$\boldsymbol{V}_{\boldsymbol{r}}$} \\
\hline Cross-section moment & 0.03 \\
\hline Cross-section area & 0.0237 \\
\hline Concrete strength of the mounted slab & 0.082 \\
\hline Mounted slab reinforcement & 0.035 \\
\hline Concrete strength of span slabs & 0.117 \\
\hline Span reinforcement & 0.05 \\
\hline Influence line length & 0.0465 \\
\hline Uncertainty factor of the model & 0.02 \\
\hline
\end{tabular}

In order to define the mathematical expectation of the generalized safety factor the span was loaded with various combinations of temporary loads by diagrams H-30 (according to Building Specifications CH 200-62), A-11 (the load from a convoy of two-axle 22-ton trucks) and HK-80 (according to State Building Norms in Production ДБН В.1.2-15:2009). The reliability was evaluated by the maximum design moment in the existing span slabs $M_{s l}$ and was equal to $514.8 \mathrm{kNm}$ (Table 3). 
Table 3. Results of the calculation.

\begin{tabular}{|c|c|c|c|c|}
\hline \multirow{2}{*}{ Force } & Constant loads & A-11 & HK-80 & H-30 \\
\cline { 2 - 5 } & \multicolumn{4}{|c|}{$\mathrm{kNm}$} \\
\hline$M_{\text {init }}$ & 323.9 & 602.2 & 483.3 & 524.4 \\
\hline$M_{\text {tot }}$ & 366.3 & 643.4 & 532.3 & 591.7 \\
\hline$M_{s l}$ & 351.7 & 514.8 & 453.5 & 493.2 \\
\hline$M_{m s l}$ & 14.6 & 128.6 & 78.8 & 98.5 \\
\hline
\end{tabular}

The results of the calculation are presented in the paper as force lines, obtained by the method of finite elements built for the vulnerable section of a span (Fig. 5). Generally, the vulnerable section was situated in the middle of the slab and searched by changing the temporary loads along and across the traffic way. The summary data of the calculation with a consideration of a 900-day long-term creep are given in Table 3. The maximum bending moment in slabs for the initial structural state $M_{\text {init }}$ was defined as a solution to a separate task. The bending moment to the mounted slab $M_{m s l}$ was defined as the difference between the total moment $M_{\text {tot }}$ and the moment to the existing slabs $M_{s l}$.

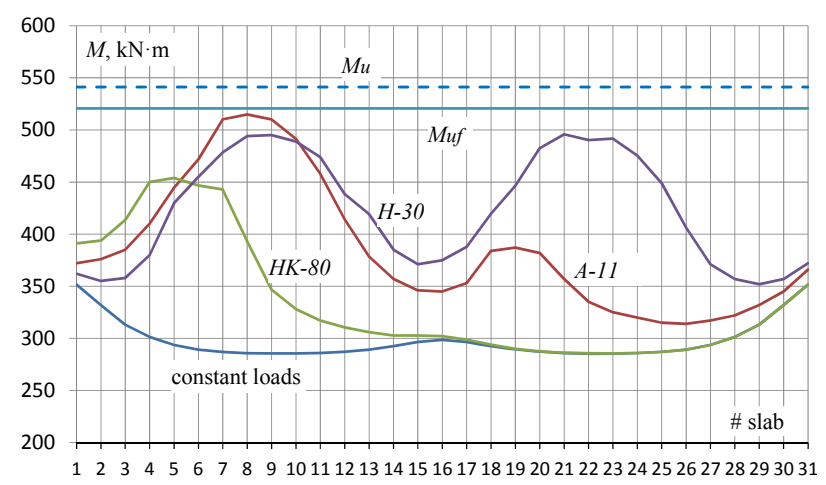

Fig. 5. The force lines (moments) for the existing span slabs after the modernization.

On the basis of the load calculation made and statistic models taken, the authors calculated the safety factor. In this case the values were: $V_{q}=0.4243 ; V_{r}=0.1679$; $B_{q}=0.5896 ; B_{r}=1.3799 ; \gamma=2.4607 ; \beta=2.4665$. Later, by means of the tables of Laplace transforms, the reliability was evaluated as equal to $P=0.9931$. Thus, the probability of a trouble-free operation of the overpass corresponded to Operational State 3.

The result obtained corresponded to a thickness of the mounted slab of $150 \mathrm{~mm}$, which was obtained by stepwise approximation. The diagram and parameters of the mounted slab reinforcement were set for each design cycle according to the acting loads.

As the calculation demonstrated, consideration of evolutionary changes in the span model led to a lower impact of the mounted slab on the carrying capacity of the modernized structure. A fraction of the total bending moment from all constant loads and sustained by a mounted slab was $4 \%$, the same from the load A-11 according to the diagram (with consideration of the constant load and passersby) was $20 \%$, from the load HK- 80 it was $15 \%$, and from the load $\mathrm{H}-30$ it was $17 \%$.

\section{Conclusion}

The modelling method proposed made it possible to establish the real carrying capacity of the overpass after modernization and assign the most effective reinforcement structure satisfying the present loads of HK-80 and A-11.

The taken approach to consider the creep included the control algorithm through the structural properties of concrete. It was established that long-term processes in the composite section influenced the stress-strain behavior. The efficiency of the modernization method does not decrease with time, and depends on a rational concrete mix and the optimum correlation of the structural parameters.

\section{References}

1. Bridges and pipes. Rules of designing: DBN V.2.314:2006. K.: Ministerstvo budivnitstva, arhitekturi ta zhitlovo-komunalnogo gospodarstva, 359 (2006)

2. A. Lobiak, G. Vatulia, Ye. Orel, Simulation of performance of circular CFST columns under shorttime and long-time load. 6th International Scientific Conference "Reliability and Durability of Railway Transport Engineering Structures and Buildings" Transbud 2017. MATEC Web of Conferences, 116, 02036 (2017)

3. A.N. Plugin, A.A. Plugin, O. Kalinin et al., Fundamentals of theory of solidification, strength, fracture and durability of Portland cement, concrete, and structures of them (in Russian), Naukova dumka, Kyiv, 3, 287 (2012)

4. A. Gorodetsky, Computer models of structures, Fact, Kyiv, 394 (2007)

5. Design of Concrete Structures - Part 1-1: General Rules and Rules for buildings EN 1992-1-1. Eurocode 2, Brussels, 227 (2004)

6. Instructions on assessment and forecasting the operational condition of road bridges (in Ukrainian), DSTU-N B.V.2.3-23:2013. K.: Minregion Ukrayiny, 54, (2013).

7. A. Rzhanitsyin, Reliability calculation theory for structures (in Russian), 239 (Stroyizdat, Moskva, 1978) 